\title{
MEMÓRIAS, TRANSFORMAÇÕES E MODERNIDADES NA METRÓPOLE AMAZÔNICA: \\ UMA BREVE HISTÓRIA DO TRANSPORTE COLETIVO EM MANAUS E BELÉM
}

\author{
REMINISCENCE, TRANSFORMATIONS AND MODERNITY IN THE \\ AMAZONIAN METROPOLIS: \\ A BRIEFING HISTORY OF COLLECTIVE TRANSPORT IN MANAUS AND \\ BELÉM
}

Gabriel Augusto Nogueira dos Santos ${ }^{1}$ Orcid: 0000-0002-1959-6313

\section{Resumo}

A organização do transporte de passageiros atende as diversas necessidades dos agentes envolvidos no modo de vida urbano. Ao longo dos anos, as necessidades de ir e vir, além dos fluxos e fixos envolvendo bens e serviços, ocasionaram mudanças e adaptações frente ao transporte de passageiro. Nos primórdios, caracterizado pela tração animal e hoje, com as mais diversas opções e tipologias de veículos, a modernidade se fez presente no transporte de passageiros. A partir desse processo evolutivo, nota-se as organizações nas cidades de Manaus e Belém, tratadas por processos históricos e econômicos interligados, adaptados as suas necessidades e formatos urbanos, em um aspecto de embelezamento, posteriormente, ocasionando novas funções e novos formatos de ocupações. Com isso, nota-se o envolvimento dos agentes públicos e privados, seja pela regulação ou pelo interesse nas operações do transporte coletivo de passageiros, que se adaptam as necessidades e também as problemáticas envolvendo o planejamento urbano, que impactam diretamente no modal de transporte coletivo.

Palavras-Chaves: transporte urbano, história, metrópole, Amazônia

\begin{abstract}
The passenger transport organization meets the diverse needs of the agents involved in the urban way of life. Over the years, the needs to come and go, in addition to the flows and fixed costs involving goods and services, have caused changes and adaptations in passenger transport relationships. In the early days, characterized by animal traction and today, with the most diverse options and types of vehicles, modernity was present in passenger transport. From this evolution process, organizations in the cities of Manaus and Belem can be seen, treated by interconnected historical and economic processes, adapted to their needs and urban formats, in an aspect of beautification, subsequently causing new functions and new occupations formats. Thus, the involvement of public and private agents can be noted, either by regulation or by the interest in collective passenger transport operations, which adapt to the needs and also the problems involving urban planning, which directly impact the collective transport.
\end{abstract}

Key-words: urban transport, history, metropolis, amazonia.

\footnotetext{
${ }^{1}$ Mestrando em Geografia pela Universidade Federal do Amazonas. Graduado em Geografia (Bacharelado) pela Universidade Federal do Amazonas e Graduando em Tecnologia em Logística pelo Instituto Federal de Educação, Ciência e Tecnologia do Amazonas. E-mail: nogueira.gabriel01@gmail.com

Revista do Instituto Histórico e Geográfico do Pará (IHGP), (ISSN: 2359-0831 - on line), Belém, v. 07, n. 02 , p. 96 118, jul.-dez. / 2020.
} 


\section{INTRODUÇÃO}

A notoriedade que a região Amazônica ganhou a partir da segunda metade do século XIX, provocou mudanças nas conjunturas do ir e vir das cidades na região. Nesse contexto, o fortalecimento das cidades de Belém e Manaus em relação ao comércio gomífero, as colocou em um âmbito de modernidade e desenvolvimento, tanto no Brasil, quanto perante ao mundo.

A partir disso, a modernidade passou a se tornar cada vez mais vigente, tanto em um aspecto urbanístico e de embelezamento, quanto perante aos novos formatos de circulação. Nesse contexto, Lima (2005, p.47), destaca a cidade como um local fixo em relação a produção do capital, cuja expansão capitalista tornou-se necessária a migração populacional para a sua sobrevivência, contribuindo para o aumento de demandas e em contrapartida, uma necessidade maior em relação ao transporte de passageiros, predominante até os dias atuais.

Santos (2020, p.26), destaca no processo, o interesse estrangeiro em comandar os serviços urbanos, contribuindo também, para o surgimento de novas categorias de trabalhadores. A partir disso, nota-se ao longo dos anos, em uma conjuntura histórica e geográfica, a evolução do Sistema de Transporte de Passageiros, vinculadas as necessidades, mas também, enfrentando as dificuldades existentes em relação a um planejamento urbano adequado.

Com isso, nota-se o transporte de passageiros como principal vetor do desenvolvimento das cidades, principalmente pelas suas transformações e também, pela correspondência com as realidades vigentes em cada local. A evolução do modal de transporte acompanha as necessidades da cidade, mesmo que oriundas em aspectos deficitários, conforme vimos em processos recentes, a partir do advento de novas políticas na região Amazônica, além dos processos de urbanização difusa e o surgimento de novas centralidades urbanas em relação a bens, serviços, sujeitos e ações, conforme analisa Santos (2004).

A interligação de Belém e Manaus nessa evolução, pode ser entendida também, a partir dos seus contextos históricos de implementação da eletricidade, o pioneirismo da segunda cidade em relação a esse serviço. Além disso, é importante frisar nessa evolução do transporte, os conceitos envolvendo tração animal, elétrica e posteriormente, os motorizados, que são a atual configuração do sistema de transporte vigente em muitas cidades.

Nesse artigo, o objetivo é acompanhar os diversos panoramas vigentes, com as inserções privadas e públicas, características de sistemas econômicos e políticos em vigência. Com isso, a modernidade $\mathrm{x}$ questões urbanas podem serem colocadas em contraposições, ocasionadas pelas necessidades de uso e ocupação do solo, mas também, das preferências ou faltas de alternativas em relação ao transporte coletivo nas cidades em questão. 


\section{DO PIONEIRISMO ENERGÉTICO NA AMAZÔNIA AO ARTICULADO - A EVOLUÇÃO DA CIDADE DE MANAUS}

- Serviço de Transporte de Bondes (1896 - 1957)

Em primeiro momento, é necessário relacionar a inserção do primeiro modal de transporte urbano em Manaus, com a criação da rede elétrica na cidade de Manaus e seu pioneirismo na região Amazônica. Lemos (2007, p.124) e Magalhães (2014, p.33), destaca nessa criação, o contrato datado de 1893 e posteriormente, a inauguração em 1896, sendo destacado o nome do indivíduo Charles Flint, como proprietário do ramo energético na cidade de Manaus.

Segundo Magalhães (2014, p.34), o serviço de bonde iniciou de forma provisória em fevereiro de 1896. Além disso, é destacado entre os anos de 1897 a 1909, a criação de novas linhas, com destino aos bairros de Flores, Cachoeirinha, além da primeira empresa a exercer o controle, neste caso a Manaós Railway Company.

Nota-se nesse processo, a iminência de reclamações perante ao serviço, ocasionado pela falta de manutenção dos trilhos e também, pelos acidentes causados por excesso de velocidade, conforme destacado em Oliveira e Magalhães (2003, p.49). Apesar dos incentivos dados pelos governos estaduais desde o início da operação, a empresa em questão não conseguiu atender as necessidades expressas em contrato.

Face ao ar cosmopolita de Manaus, em 1908, a empresa Manaós Tramways (figura 01), se tornou a responsável pelo serviço de bondes, com uma concessão de 60 anos do serviço. Santos (2020, p.27), destaca nesse processo, a inserção do capital estrangeiro como um dos aspectos que oportunizou a questão do trabalho para os moradores da cidade de Manaus e também a expansão das linhas para a área do Cemitério Municipal São João Batista e também ao Plano Inclinado, hoje, bairro Nossa Senhora Aparecida.

Figura 01: Encomenda de bondes da Manaós Tramways oriundos de Preston, Inglaterra

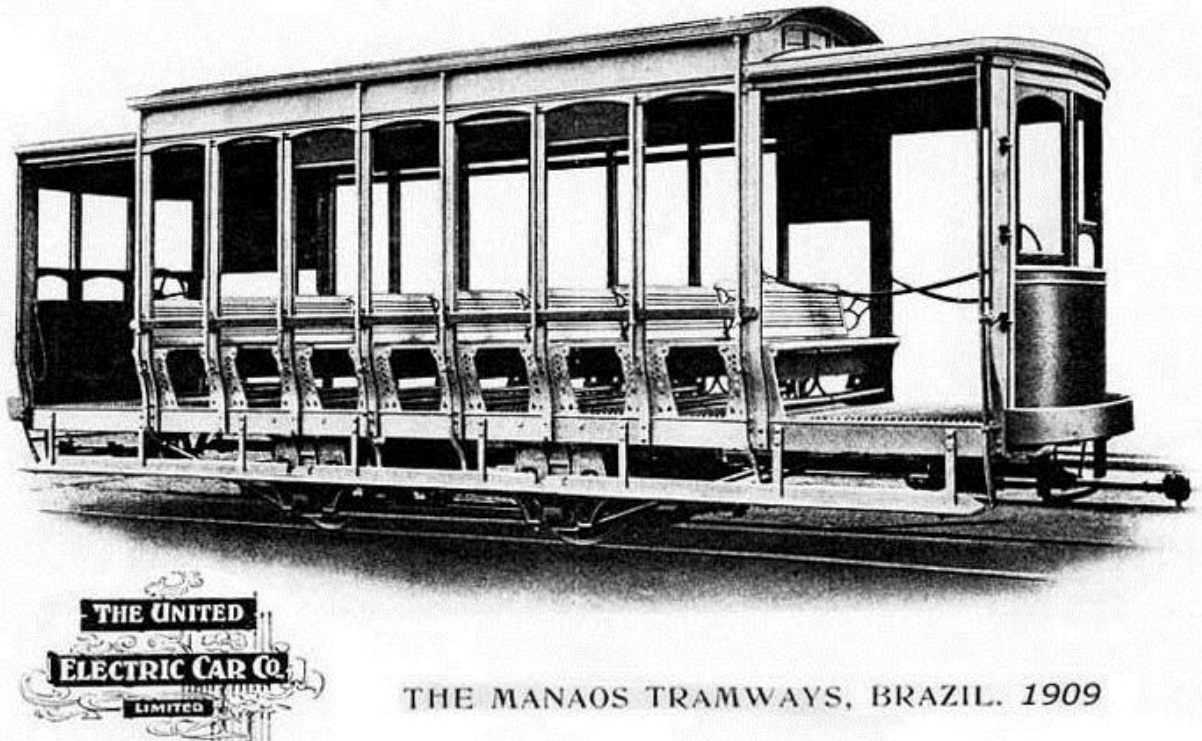

Créditos: Acervo de Durango Duarte

Revista do Instituto Histórico e Geográfico do Pará (IHGP), (ISSN: 2359-0831 - on line), Belém, v. 07, n. 02 , p. 96 118, jul.-dez. / 2020. 
Os serviços ofertados tiveram uma regularidade até o final do período conhecido como ciclo da borracha e passaram a sofrer constantes problemáticas em relação a seu funcionamento. Nessa conjuntura, é destacada também a falta de interesse da empresa operante no serviço, tanto de bondes, quanto de luz elétrica na cidade. Nesse contexto, Magalhães (2014, p.65), destaca as principais conjunturas das visões operárias em relação a estrutura da empresa operante do serviço, simbolizando ruínas e também um perigo a vida da população de Manaus.

É importante ressaltar durante essas problemáticas de operação, atreladas aos problemas da borracha e a diminuição do número de usuários, aliados ao esvaziamento urbano, as questões citadas sobre o operário e os movimentos de trabalhadores, que ganhavam notoriedade nesse período. Santos (2020), destaca nesse contexto, os movimentos de trabalhadores e as suas pautas grevistas, em um contexto de disputas envolvendo os contextos de operação estrangeira e também as longas jornadas de trabalho vigentes.

As interrupções de serviços de transporte na época, passaram por diversas fases, atreladas principalmente, as crises no serviço de fornecimento de energia elétrica e também a falta de investimentos do sistema. Apesar de novas configurações econômicas existentes na época da II Guerra Mundial (1939-1945) o serviço ainda não se tornou estável. Magalhães (2014, p.75), destacava também o papel da imprensa no noticiar das reclamações e a omissão do poder público em ampliar e também contribuir para a sobrevivência dos bondes na capital manauense.

Entre os anos de 1946 a 1950, o serviço de bondes (figura 02) estavam em franca problemática, que as conjunturas políticas nacionais estavam se tornando presentes nessa crise, principalmente no âmbito de uma intervenção governamental. Apesar da situação, a empresa ainda continuava em sua penúria, o que contribuiu para a quebra de contrato no ano de 1950 e todo o seu patrimônio, ser repassado para o Governo do Estado do Amazonas, que estava ganhando ares democráticos após o fim da Era Vargas.

Figura 02: Operação do serviço de bondes nos anos 1940

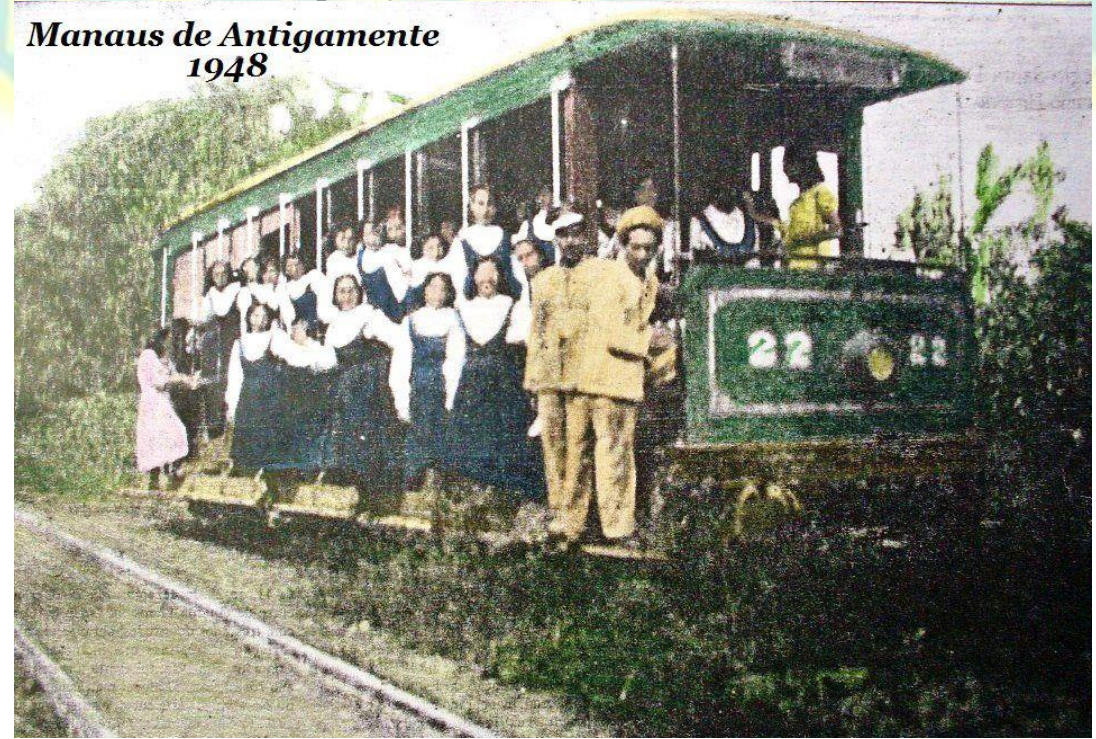

Créditos: Manaus de Antigamente

Revista do Instituto Histórico e Geográfico do Pará (IHGP), (ISSN: 2359-0831 - on line), Belém, v. 07, n. 02, p. 96 118, jul.-dez. / 2020. 
Entre o curto espaço de tempo entre os anos de 1950 a 1957, o serviço foi administrado pelos Serviços Elétricos do Amazonas e posteriormente, pela Companhia Energética de Manaus. Nesse período, o investimento nulo, aliado as crises energéticas que passou a cidade de Manaus, o sistema ficou suspenso entre os anos de 1952 a 1955, sendo reativado em caráter mínimo até 1957, quando se pensou em uma empresa pública de Transportes, a Transportamazon, mas sem interesse no serviço e sim, no serviço por ônibus, o que decretou enfim, a sua falência e desativação, conforme Magalhães (2014), destaca, sem registros e de uma forma decadente.

\section{- Serviço de Ônibus: os primeiros formatos (1947 - 1980)}

A entrada do serviço por ônibus começou como uma alternativa às problemáticas da administração do serviço de Bondes, ocasionadas desde o fim do período áureo da borracha e estavam interligadas com o fornecimento de energia elétrica. Em seus primórdios, os serviços por ônibus eram realizados de formas precárias, principalmente pelos primeiros modelos, à época adaptados de chassis de caminhões e despreparos por parte dos condutores a dirigir.

É destacado também por Lima (2005) e Magalhães (2014, p.78) a hegemonia total da concessionária de Bondes, na qual compraram os primeiros carros da iniciativa privada para mantê-los sem circulação. Com isso, nota-se que apesar da precariedade já citada anteriormente, o monopólio do transporte em Manaus deveria ser mantido a qualquer custo, transformando essa frota em sucata posteriormente, enquanto que chassis de madeiras sem condição operavam na cidade sem um aparato de regulação, enquanto que o serviço de bondes se afundava cada vez mais na cidade.

Ao longo dos anos 1940 e 1950, apesar do avanço do transporte coletivo, muitas problemáticas continuaram, principalmente relacionadas aos horários e as linhas existentes na cidade, o surgimento do transporte denominadas de "lotações" ou "expressos", fora a precarização dos serviços de bonde. Ab'Sáber (1953), em seus estudos relacionados à cidade de Manaus já mostra uma rede de transportes a se formar, tendo como ponto de partida, a Praça Oswaldo Cruz, na área central de Manaus, conforme figura abaixo. 
Figura 03: Transporte Coletivo na Área da Praça Oswaldo Cruz

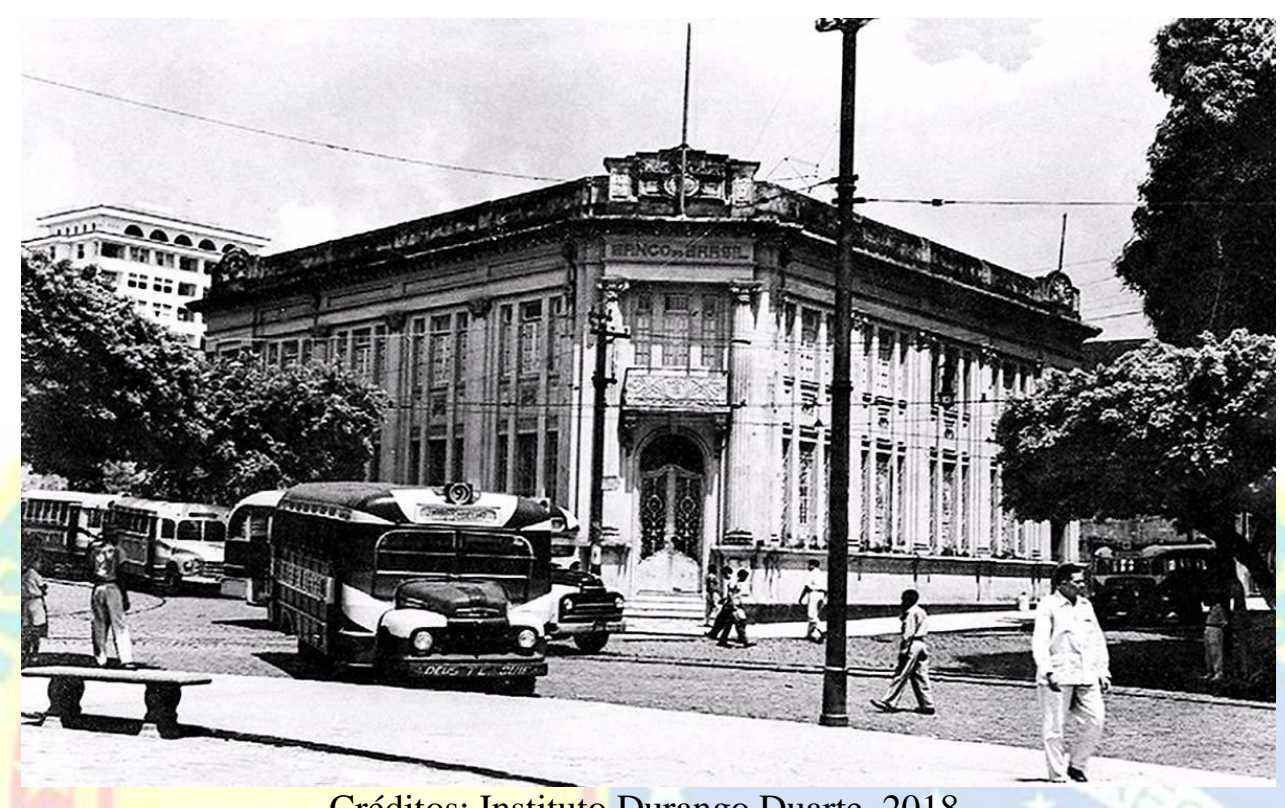

Nesse contexto, as montagens dos chassis eram realizadas em oficinas e outros modelos, oriundos de outros estados. Magalhães (2014, p.83), destaca nesse contexto, uma originalidade dos proprietários desses carros, trazendo em nome, algo que leve a sua alusão nas ruas da cidade. Surgiram vários ônibus nessa configuração como o Boa Sorte, Clíper, mas o que ganhou notoriedade nessa conjuntura, foi o Zeppelin (figura 04), relacionado também ao tamanho e formato, na qual parecia o antigo dirigível existente nos anos 1930.

Figura 04: Zeppelin em frente do Rio Negro Clube

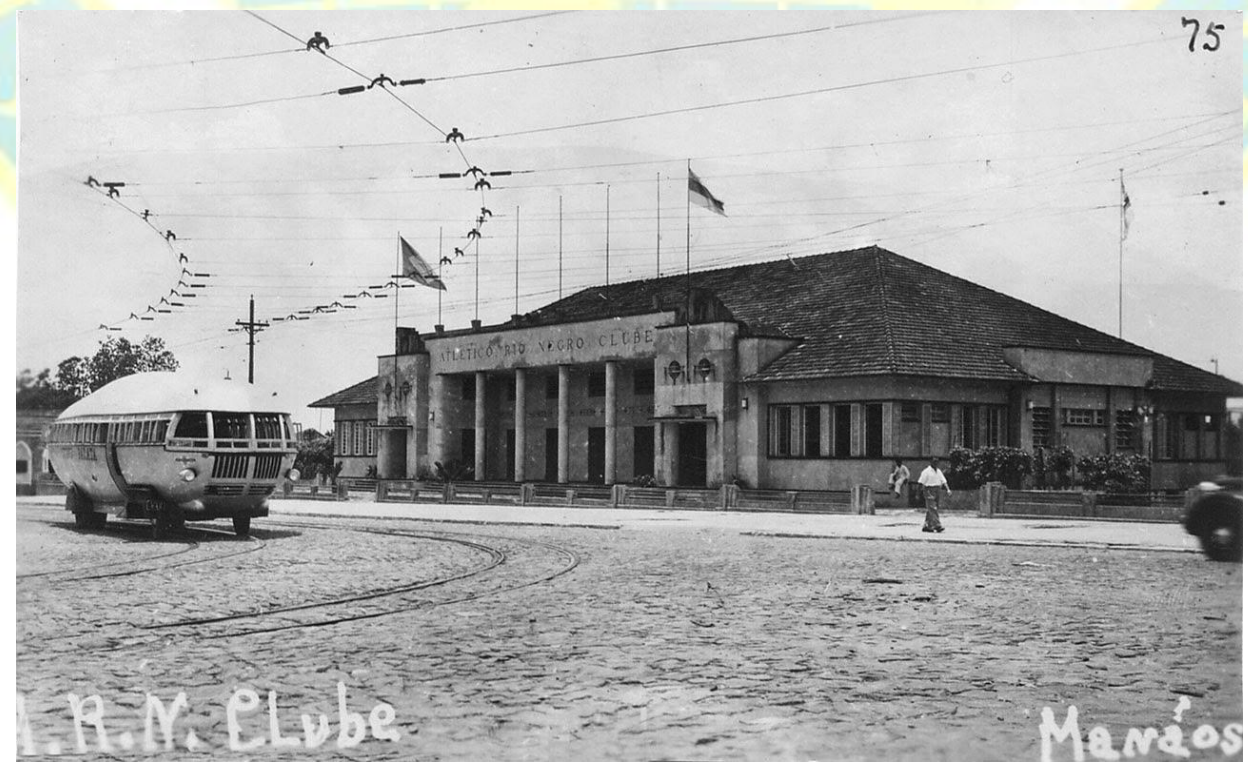

Créditos: História de Antigamente 
Além dos ônibus convencionais, a cidade de Manaus passou a contar com as "lotações" ou "expressos", que faziam esse serviço de formas mais rápidas, baseadas em uma concorrência que ocasionava muitos acidentes. A partir disso, é criado os serviços de trânsito, para o controle das normativas e em contrapartida das condições de trabalho e aspectos viárias, é datada a criação dos Sindicato dos Trabalhadores em Carris Urbanos e a Associação de Proprietários de Transportes Coletivos de Manaus, cuja situação estavam englobadas os aspectos operários e também das condições viárias para a oferta do serviço de transporte coletivo de Manaus.

Entre os anos de 1957 - 1971, existiu a Transportamazon (Transporte Amazonas S.A.), empresa de transportes pública em Manaus, fundamentada em aspectos de sociedade mista e tinha como objetivo de atuar no transporte terrestre, fluvial e aéreo no Amazonas. Entretanto, ao longo da sua curta jornada, se dedicou exclusivamente ao transporte urbano de passageiros jornada, conforme descrevem Magalhães (2014) e Duarte (2018), conforme figura abaixo.

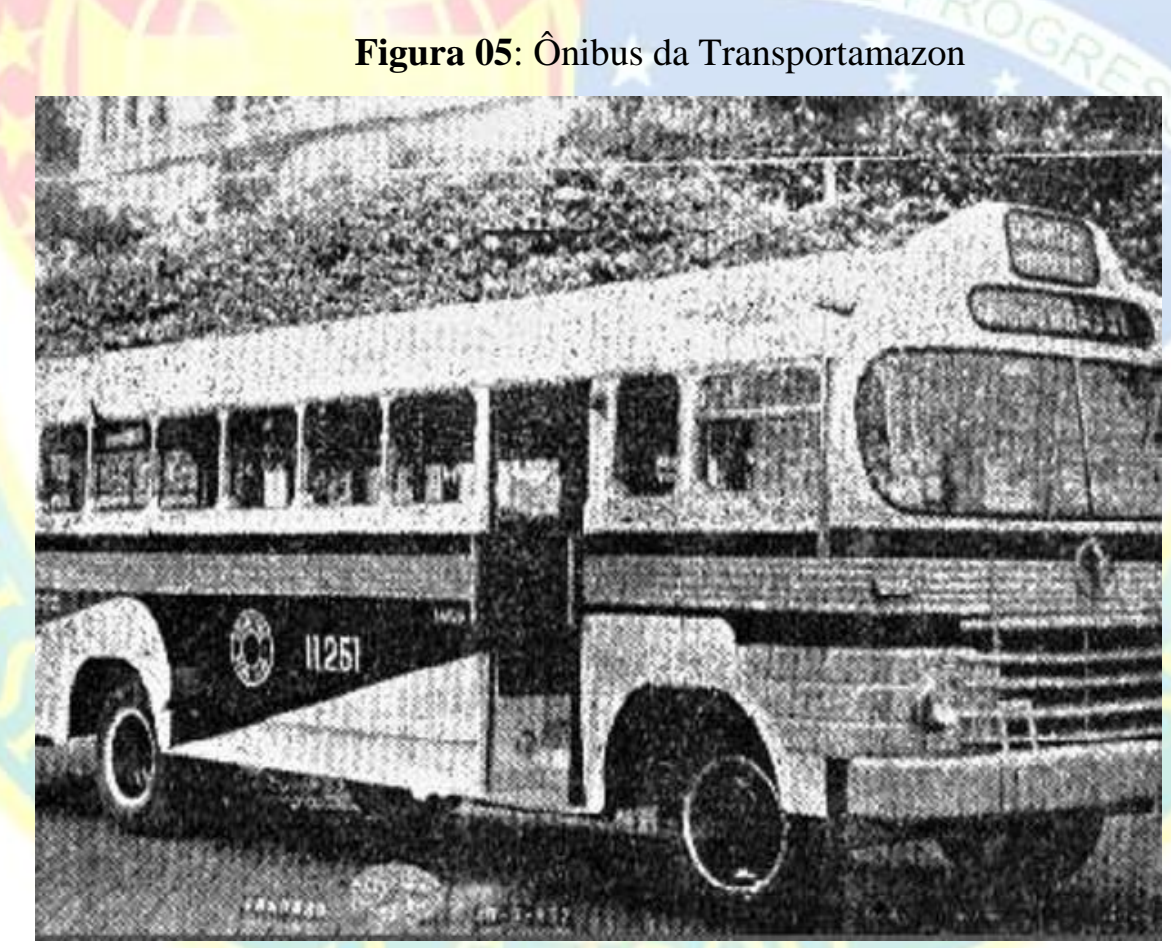

Créditos: Magalhães (2014)

Ao longo dos anos que a empresa existiu, Magalhães (2014) ressaltou as problemáticas existentes em relação à operação da empresa, destacadas pela imprensa local. Além disso, os diversos governos que a empresa passou, tanto em esferas democráticas, quanto militares, contribuíram mais para a derrocada dessa estatização da empresa, apesar dos planos desenvolvidos e linhas sustentadas para o atender da população. Em contrapartida, o transporte realizado por carros privados, eram considerados de melhor qualidade, em detrimento do serviço público, que estava fadado ao sucateamento e a posterior extinção, tendo um patrimônio considerado irrecuperável, conforme destaca Duarte (2018). 
Nesse intervalo entre os anos de 1970 e 1980, favoreceu o surgimento de diversas empresas e viações. Até o ano de 1975, a organização do transporte coletivo era feita pelo Departamento de Estradas e Rodagens do Amazonas, sendo passado posteriormente, para a Prefeitura de Manaus. Nesse contexto, entram em cena as empresas Soltur e Viação Ana Cássia (figura 06), consideradas as maiores daquele período, além de outras como a Constatinópolis, Ajuricaba, Monte Ararate. Lima (2005, p.58), destaca nesse contexto, a expansão do capital em relação a compra e venda de empresas, condicionadas aos interesses do empresário na operação.

Figura 06: Viação Ana Cássia na operação da linha do antigo Aeroporto Ponta Pelada em 1973

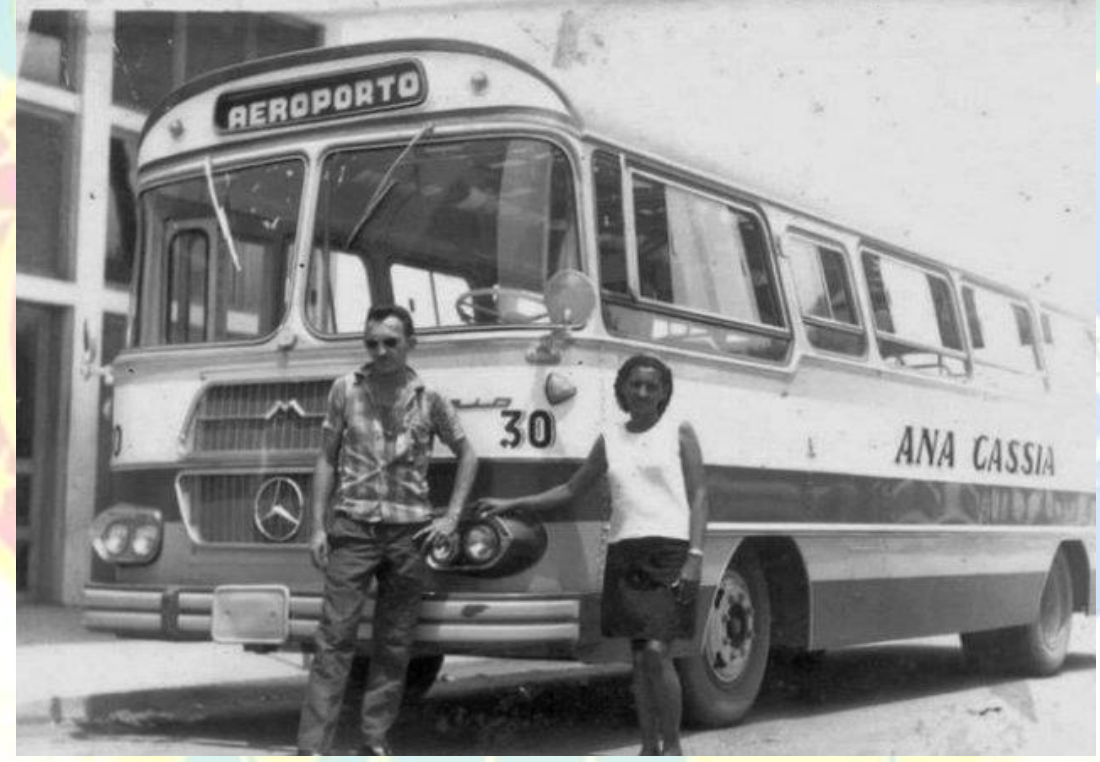

Créditos: Manaus de Antigamente

Além disso, Magalhães (2014), destaca também os projetos de linhas circulares para as áreas em expansão, a época o bairro Distrito Industrial e as divisões tarifárias em A, B e C, vinculada a bairros mais perto do Centro e bairros mais afastados. No entanto, apenas a segunda situação se tornou concreta, posteriormente, ainda em meio a crises do sistema, novas transformações foram sendo exercidas, principalmente em frota e em número de empresas operantes.

Nesse período dos anos 1970, a frota de ônibus em Manaus oscilava entre os mais de 250 carros disponíveis para a operação, já em formato metálico, a partir das pressões do poder público. Mal se pensava, que a partir dos anos 1980, outras configurações passariam a surgir, aliadas também com as transformações empresariais existentes em âmbito local e regional.

\section{- Serviço de Ônibus: empresariado local x nacional e os primeiros projetos (1980 - 1995)}

O envolvimento do estado passou a se tornar mais realidade após a delimitação e criação do sistema de transporte coletivo em Manaus nos anos 1950, na qual Magalhães (2014) ressalta o controle por parte das Secretarias de Viação e Obras Públicas, até a criação da Empresa Municipal de Transportes Urbanos Revista do Instituto Histórico e Geográfico do Pará (IHGP), (ISSN: 2359-0831 - on line), Belém, v. 07, n. 02, p. 96 118, jul.-dez. / 2020. 
(EMTU) em 1980. Com essa configuração pós anos-1980, se tornou mais consistente o gerenciamento do transporte coletivo por parte da esfera municipal.

Nesse contexto, é importante englobar o vetor de expansão norte-leste, conforme analisa Lima (2005, p.69), em um formato de ocupações iniciais com a participação do poder público, posteriormente, relacionava as áreas da Cidade Nova (Governo Estadual) e São José Operário (Prefeitura de Manaus), como locais de vetorização posterior da ocupação de novas áreas na cidade de Manaus.

Nesse contexto, o transporte da cidade de Manaus não conseguia atender a demanda e novos formatos passaram a existir. Em primeiro momento, destaca o serviço "executivo", consistente em um deslocamento com tarifas diferenciadas aos bairros da Zona Centro-Oeste, em franca ascensão e destacada como um serviço que correspondia a uma segregação, conforme analisa Lima (2005). Nesse aspecto, durou pouco, devido a iminentes problemas de lucratividade e também acerca do serviço não ser ofertado de forma adequada.

Um dos projetos de maior interesse em Manaus nos anos 1980 são os sistemas desenvolvidos pelo então prefeito Manoel Ribeiro entre os anos de 1985 a 1989. Essas conjunturas eram divididas em duas, conforme descreve Lima (2005) e Costa et al (2017): o Manecão, que circulava nos bairros da Cidade Nova, consistia em um "cavalo mecânico" e uma carroceria de ônibus acoplada e o Manequinho, que eram microônibus que circulavam nas áreas centrais e bairros adjacentes com uma diferença tarifária, sendo este último, o novo transporte alternativo na cidade de Manaus, conforme visto abaixo.

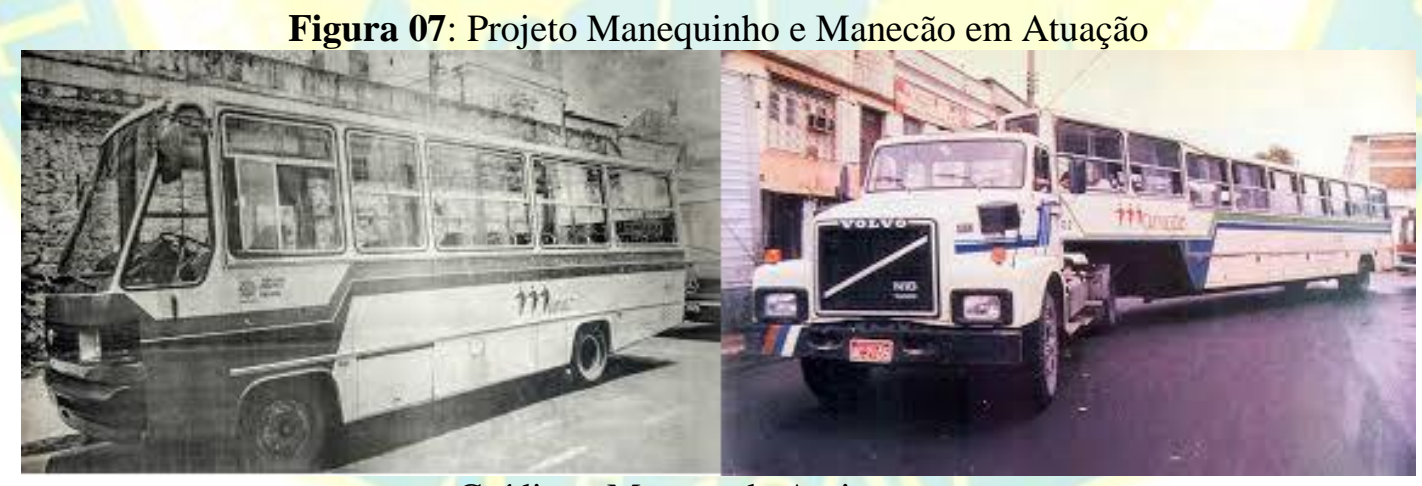

Créditos: Manaus de Antigamente

Apesar das tentativas de melhorias do serviço de transporte, os piores anos de relações entre a prefeitura e as empresas, são entre os anos de 1989 a 1994, cujo sistema se tornou problemático. Apesar das entradas de empresa como a EUCATUR, o primeiro ônibus articulado que a mesma trouxe em meados de 1991 (figura 08), as conjunturas do serviço ainda não eram atrativas. 
Figura 08: O primeiro articulado operante em Manaus

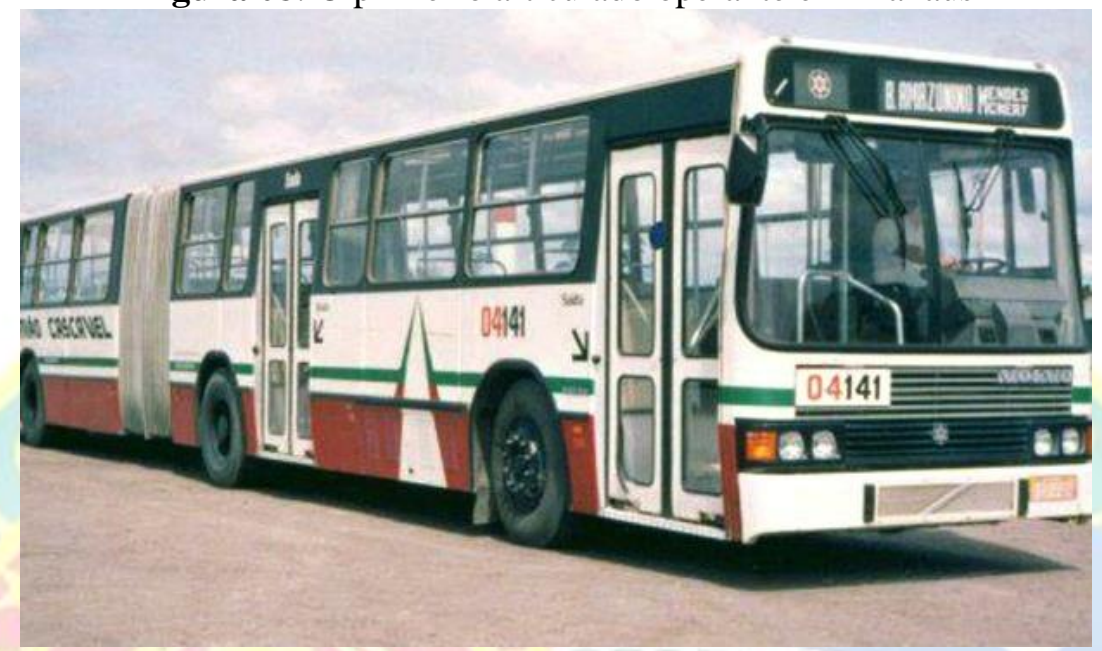

\section{Créditos: G1 Amazonas}

Nota-se nesse contexto, a extinção de empresas e a intervenção política da prefeitura no sistema, devido a necessidade de uma melhoria na frota e também, na reformulação do sistema. Nesse contexto, as concessões foram ganhando notoriedade, principalmente pela inserção de empresas oriundas de outras regiões, principalmente, detentoras de grandes conglomerados no ramo nas regiões Sul e Sudeste, conforme analisa Lima (2005) em sua construção teórica.

A partir disso, novas conjunturas e projetos passam a existir em Manaus, novas territorialidades, aliadas principalmente aos seguintes fatores: relação política de mandatários e políticas de governo, em detrimento das políticas de estado voltadas ao transporte coletivo.

\section{- Serviço de Ônibus: Projeto Expresso, Sistema Complementar e BRS Manaus (1996 - atualmente)}

Com as iminentes crises até metade dos anos 1990 e as novas concessões de transporte coletivo, as áreas que foram surgindo na cidade de Manaus se viam na necessidade de transporte. Com isso, a modalidade informal do transporte coletivo, caracterizada principalmente pela falta de regulação dos órgãos públicos, começaram a surgir na cidade de Manaus, em um novo formato voltado ao sistema alternativo.

Entre os anos de 1996 a 2000, a cidade de Manaus contou com uma nova modalidade de transporte alternativo, mas desta vez, vinculada com os bairros mais afastados e periféricos. As Kombi-lotação (figura 08), começaram a surgir nesse período e ganharam sua primeira regulamentação em fins dos anos de 1999, principalmente destacada como um sistema complementar. 
Figura 09: Primeiras Lotações a operarem em Manaus

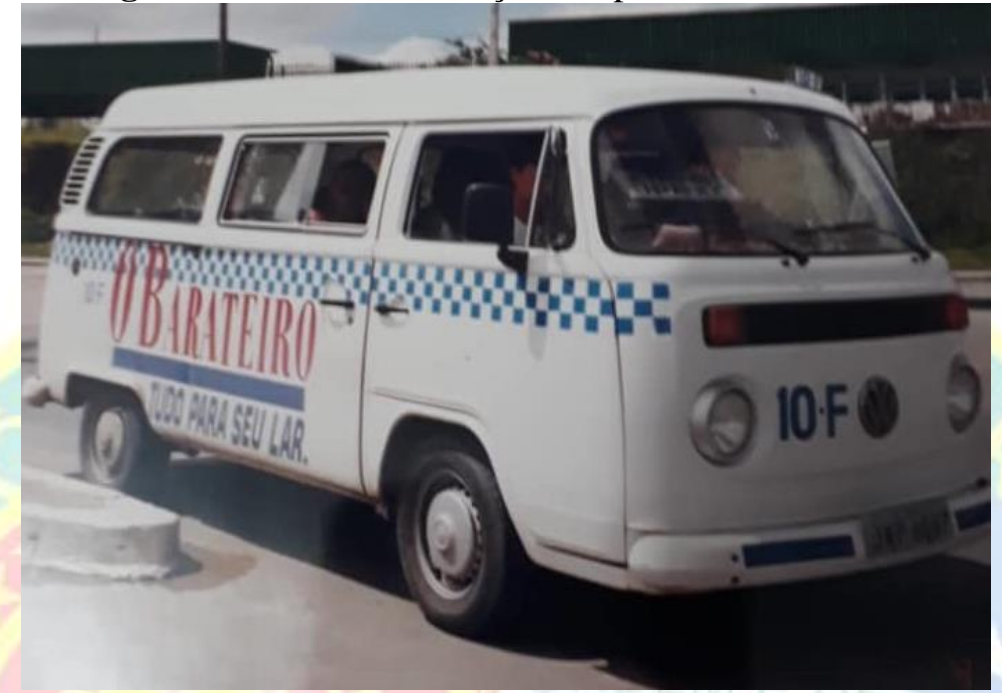

No início dos anos 2000, Manaus era composta por cerca de 1149 ônibus, conforme dados da SMTU (2019) e mudanças passaram a surgir. Com isso, o Projeto Expresso (figura 10), baseado no Sistema BRT de Curitiba, passou a ser cogitado, principalmente relacionado a criação de corredores específicos. Rodrigues (2017), destaca nesse conceito, a redução do tempo de deslocamento das viagens e a transformação do sistema tronco alimentador.

Figura 10: Sistema Expresso em operação (2002)

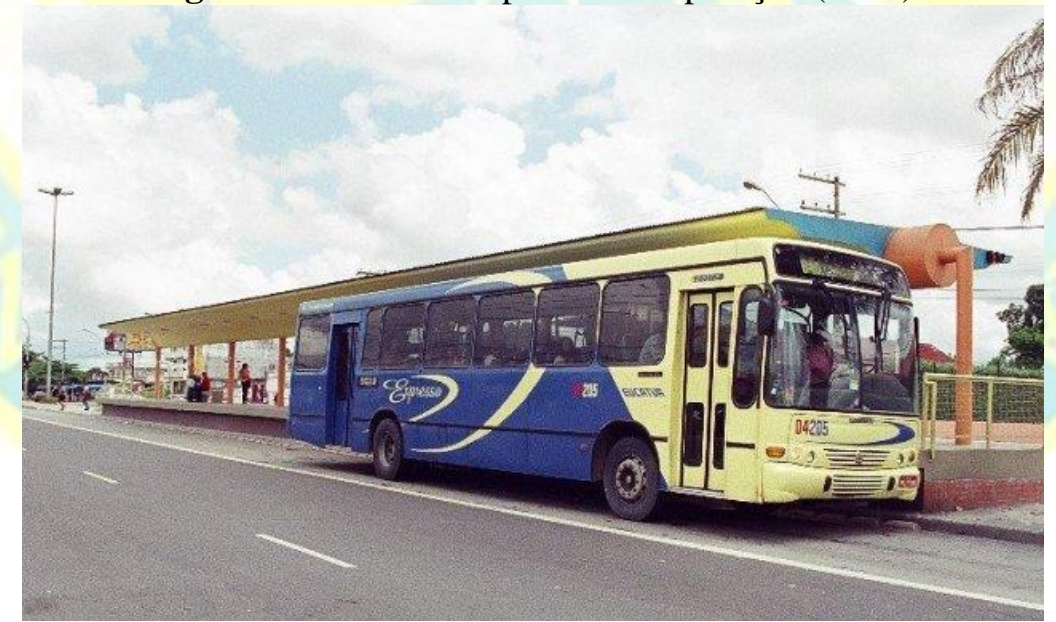

Créditos: Acervo Elioenai de Araújo/SMTU

Com isso, as novidades do sistema a partir do financiamento do BNDES, ficaram cada vez mais presentes, principalmente durante seu período de funcionamento entre os anos de 2002 a 2004. Entretanto, devido a falta de planejamento e questões políticas, conforme analisa Lima (2005), o projeto se tornou problemático e foi finalizado, mais uma vez mostrando a ação política como apenas algo temporário, sem uma consistência de atualização e manutenção. 
Em 2006, a EMTU foi substituída e criado o Instituto Municipal de Transportes Urbanos (IMTU), em 2006 e posterior fusão com os setores de trânsito, assim surgindo o Instituto Municipal de Trânsito e Transportes (2009), Além disso, novas reorganizações fomentaram o surgimento da Superintendência Municipal de Transportes Urbanos (SMTU), criada a partir da Lei $\mathrm{n}^{\circ}$ 1.320/2009 e ampliada em 2010. Posteriormente, em 2019, se criou o Instituto Municipal de Mobilidade Urbana, vinculando o planejamento de transportes e trânsito.

Nesse contexto de 2006 a 2019, as conjunturas do transporte coletivo de Manaus se transformaram pelos contextos licitatórios, sobretudo os de 2007, culminando com a entrada do consórcio Transmanaus e uma crise sistemática envolvendo a falta de cumprimento do contrato e posteriormente, a quebra do mesmo e a reorganização do sistema com a licitação de 2010.

Um dos marcos nesse período, se deu com a regulamentação definitiva dos Sistemas Alternativo (Amarelinhos) e Executivo em 2007, com limitação de frota e linhas a circular em Manaus (figura 10), abrangendo as áreas de atuação, afim de controlar o transporte clandestino de passageiros, massivamente presente em algumas áreas de Manaus. Apesar disso, a conjuntura atual do projeto se encontra em problemáticas de falta de renovação das concessões e entraves jurídicos, o que ocasiona uma falta de seguridade jurídica por parte dos trabalhadores e permissionários.

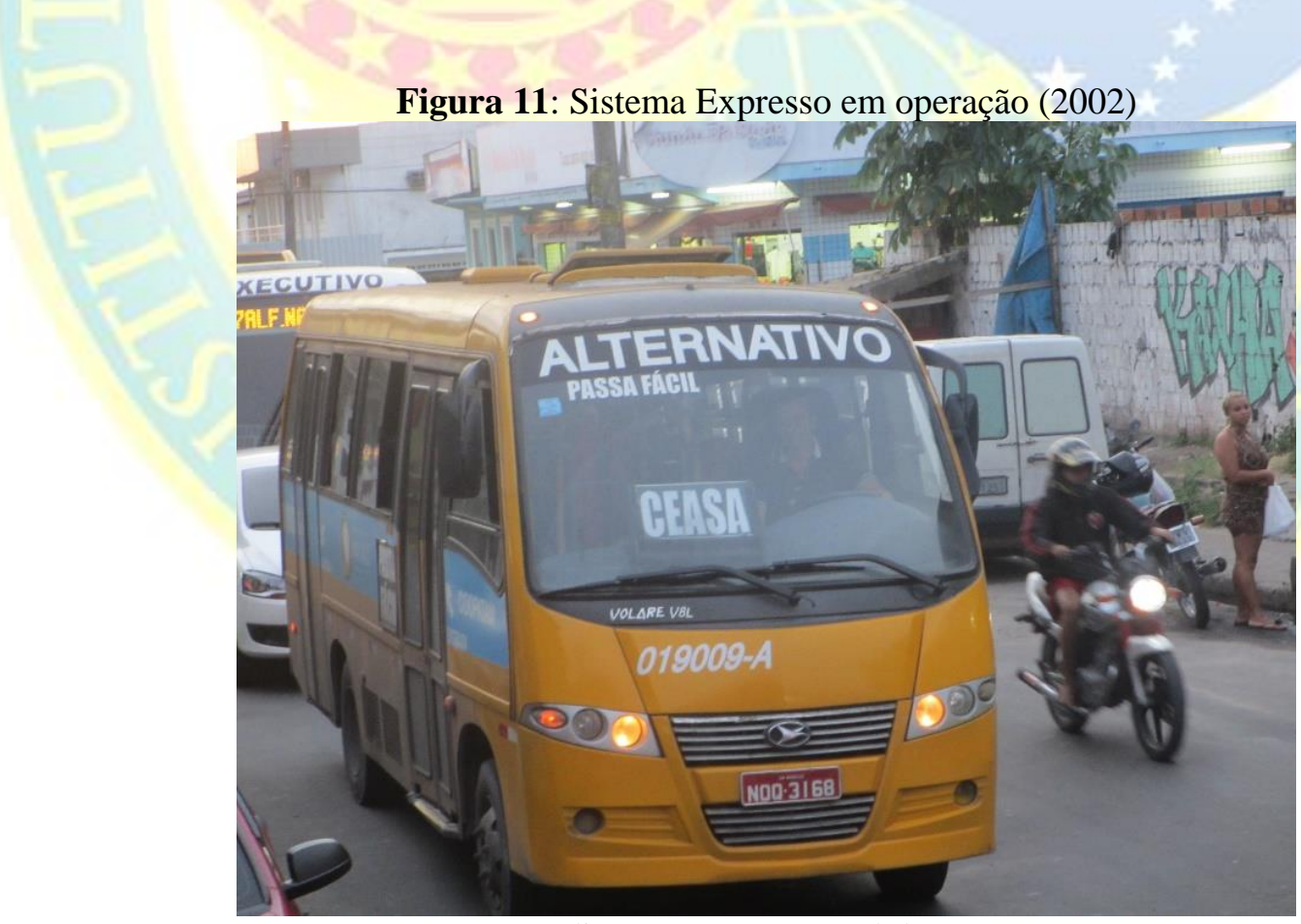

Créditos: Acervo pessoal do Autor

Outro aspecto, foi o projeto BRS Manaus, pensado a partir da estrutura do Sistema Expresso, baseada nas estações e vias segregadas. Com isso, o sistema permitiu a criação da Faixa Azul (circulação exclusiva de ônibus) e também criação dos novos corredores viários (Avenida das Torres e Avenida das Flores) para o trânsito e diminuição do tempo de percurso de viagem. 
Nota-se por tanto, as conjunturas em Manaus se baseando em transformações oriundas de crises e também, do surgimento de modais complementares. A conjuntura de Manaus é baseada principalmente nos contextos voltados a expansão urbana e também, a periferização do espaço nos círculos norte-leste, assim contribuindo para o surgimento de novas vertentes e também, em uma modernização ao mesmo tempo pioneira, quanto tardia em algumas concepções.

\section{DO FORTE DO PRESÉPIO AS ÁREAS DE EXPANSÃO E CONURBAÇÃO - HISTÓRIAS E EVOLUÇÕES EM BELÉM}

\section{- Bondes e a influência da Estrada de Ferro Belém-Bragança no transporte (1870 - 1940)}

Em aspectos relacionados ao histórico do transporte coletivo, as relações com Manaus são de suma importância entre meados do século XIX e inícios do século XX, devido ao fortalecimento da economia gomífera nas duas cidades. Os primeiros transportes existentes na cidade eram caracterizados pela disputa entre as carruagens de aluguel e os bondes, à época movida por tração animal e a vapor.

Em primeiro momento, Lemos (2007, p.144), destaca em 1871, a criação da Companhia Urbana da Estrada de Ferro Paraense, que além de ofertar serviços de tração animal, ficou responsável pela distribuição da energia elétrica na capital paraense. Já é relacionado os primeiros conflitos empresariais no setor de transporte, entre esta primeira e a Companhia de Bondes Paraense pelas áreas de atuação no transporte de passageiros.

Com a instalação da energia elétrica na cidade de Belém, gradativamente, os bondes de tração animal foram sendo substituídos pelos mais modernos da época e a sua administração ficou para a Companhia Pará Eletric, também responsável pela iluminação pública, tal como acontecia em Manaus. Essa operação, segundo Castro (2015, p.50; 2017, p.282), abastecia a cidade com cerca de 10 linhas e bondes destinados aos passageiros de $1^{\mathrm{a}}$ e $2^{\mathrm{a}}$ classe, principalmente diferenciados pelo padrão e pela estrutura de conforto aos mais abastados, notando claramente, as diferenças sociais, conforme as figuras abaixo.

Figura 12: Bondes destinados as classes (Figura $\mathrm{A}-1^{\mathrm{a}}$ Classe; Figura $\mathrm{B}-2^{\mathrm{a}}$ Classe)
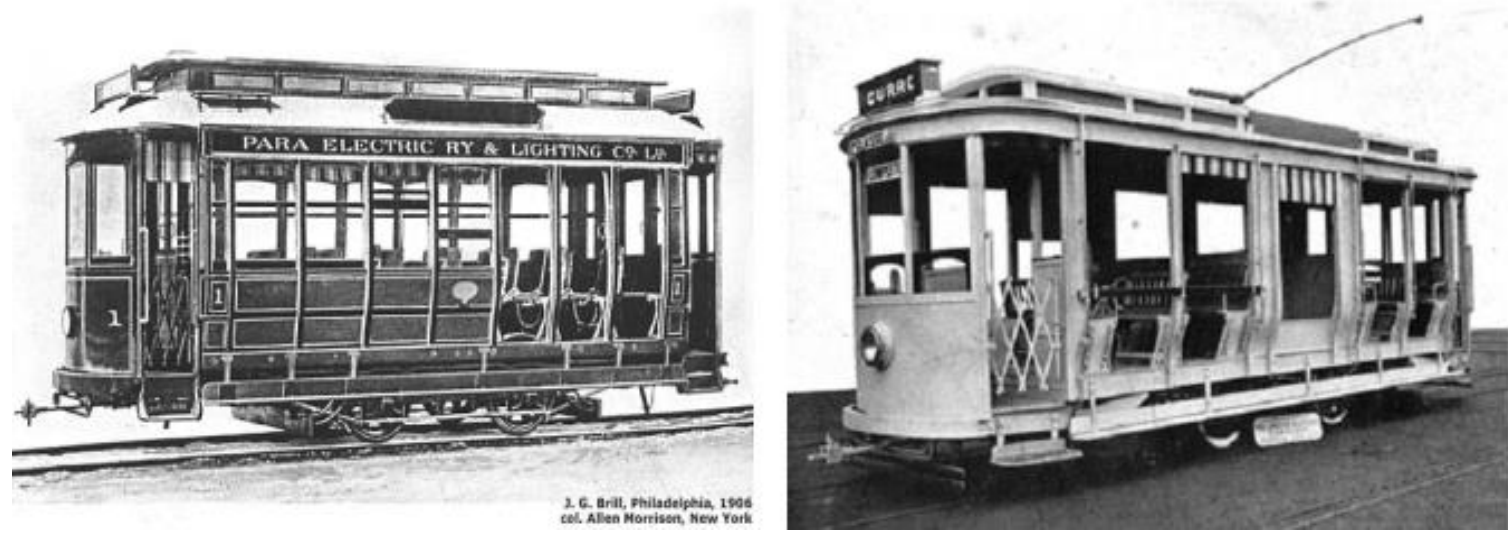

Extraído de: Lima (2008) e Castro (2015)

Revista do Instituto Histórico e Geográfico do Pará (IHGP), (ISSN: 2359-0831 - on line), Belém, v. 07, n. 02, p. 96 118, jul.-dez. / 2020. 
Em relação ao transporte por ônibus, Lima (2008, p.12) mostra que o primeiro serviço começou no ano de 1911 e logo se transformou em uma ameaça para os serviços de bondes, sobretudo devido ao seu atendimento ser focado principalmente em áreas que não havia como colocar uma infraestrutura de Bondes, segundo as análises de Pinho (2001) e Tobias et al (2008). Essas ameaças eram relacionadas principalmente ao poder de administrar essas estruturas, sendo que a dos ônibus eram vinculadas a prefeitura e a dos bondes, eram estabelecidas pela Pará Eletric. Além disso, era noticiado nesse período, os inúmeros acidentes por imprudência dos condutores de ambos.

Com o final da I Guerra Mundial, a companhia operante do serviço sofreu diversas ameaças e problemas, principalmente em relação ao sucateamento de sua frota. Nesse quesito, Mercês (1998, p.85), destaca a unificação de tarifas e também a extinção de classes. Apesar disso, as crises se tornavam cada vez mais presentes no âmbito da Pará Eletric, além das relações com as políticas nacionais, que valorizavam uma esfera mais rodoviária no transporte.

Lemos (2007, p.153), mostra que ainda nos anos de 1920 e meados dos anos de 1930, houveram renovação de frota, mesmo com veículos de segunda mão oriundos da Inglaterra, este caso destacado por Lima (2008, p.13) e ainda uma ampliação do serviço de bondes na cidade de Belém, para a Vila do Pinheiro (atual Icoaraci) e para a localidade da região do cemitério de Santa Izabel, que havia recebido energia elétrica. Nesse período, ainda houve a transformação da Pará Eletric em Companhia Elétrica Paraense e a criação da subsidiária, Companhia Paraense de Viação Geral, já com os primeiros ônibus, conforme descreve Lemos (2007, p.154).

Posteriormente, como aconteceu em Manaus, as intervenções federais no serviço e as problemáticas de sucateamento, forçaram o decreto de intervenção federal no transporte e sus suspensão provisória em meados de 1946, descritos por Mercês (1998, p.85) e Lemos (2007, p.156). Nesta suspensão, foram extintas e repassadas ao governo estadual a concessão do serviço, que ainda continuou a rodar em situação de calamidade até a sua extinção total em 1952 e trazendo os ônibus como vetores totais do desenvolvimento da cidade de Belém.

\section{- Os primeiros ônibus e as mudanças de léguas patrimoniais (1940 - 1980)}

Como já citado, os primeiros serviços de ônibus de Belém são datados dos anos 1910, mas com força total apenas com a criação da Companhia Paraense de Viação Geral e com a extinção da Pará Eletric/Companhia Energética Paraense, analisadas por Mercês e Lemos. Nessa conjuntura, Castro (2017), também destaca as problemáticas entre os serviços, principalmente no âmbito do trânsito e dos acidentes noticiados, ocasionados por imprudência e também, concorrência do serviço.

Nos anos 1950 e 1960, analisa-se o transporte em Belém e Região Metropolitana, pela presença maciça de lotações, devido a decadência e suspensão dos serviços de transporte por bondes. Além disso, os fatores de expansão urbana, favoreceram posteriormente o surgimento de empresas, alguma atuante até os 


\section{Memórias, transformações e modernidades na metrópole amazônica: \\ Uma breve história do transporte coletivo em Manaus e Belém}

dias atuais, apesar dos inúmeros problemas em relação a infraestrutura da área de circulação, conforme descreve Tobias (2005).

Junto com Manaus, diversas carrocerias entram em operação, dentre as quais, o famoso Zeppelin, circulante entre o ano de 1948 e meados dos anos 1950, masque em Belém não se teve o mesmo sucesso, principalmente por problemas técnicos, sendo repassados a outras cidades posteriormente. Destaca nesse processo, a Viação Triunfo (figura 13) e a Viação Sul-Americana, que utilizaram o modelo.

Figura 13: Zeppelin da Viação Triunfo

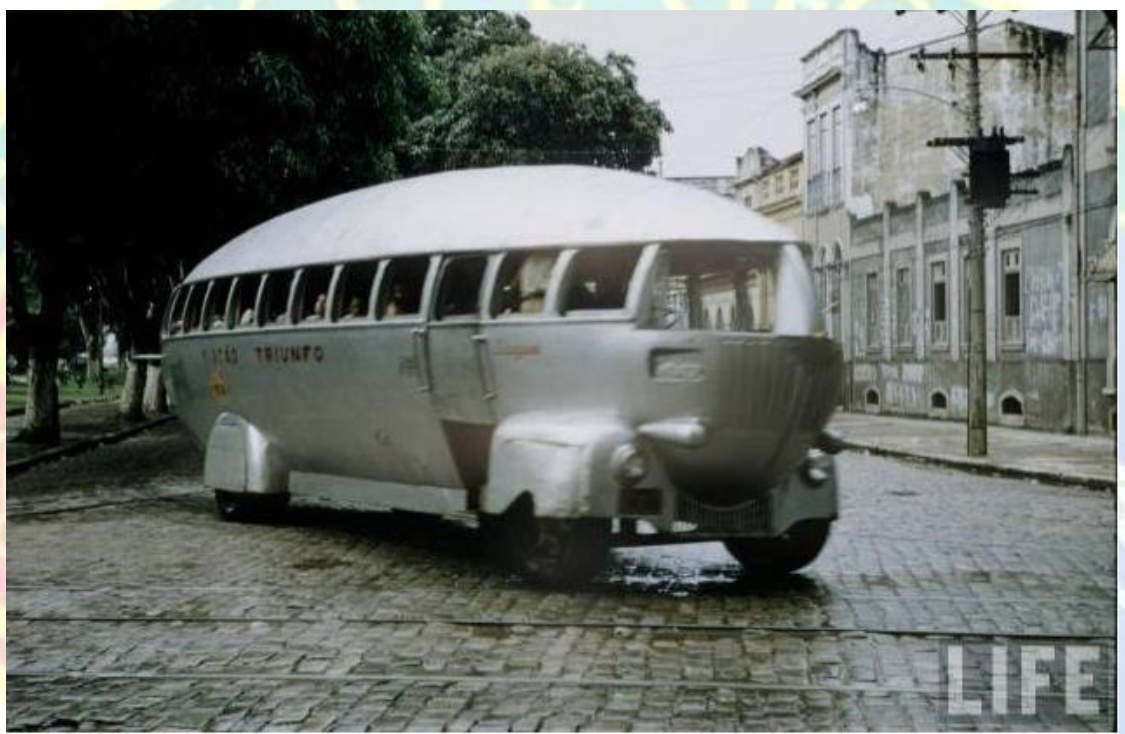

Créditos: FAU/UFPA

Posteriormente, com as frentes de expansão voltadas ao denominado Ramal do Pinheiro, um dos eixos da Estrada de Ferro Belém-Bragança, que daria origem a Rodovia Augusto Montenegro. Com isso, Mercês (2007) e Castro (2015, p.54), destaca as novas abrangências do serviço de transporte, mas de forma precária.

Até os anos 1950, a participação do estado era mínima, apenas como poder concedente, sem fiscalização e rigor na operação. Nesse período, já era visto a carroceria metálica na cidade de Belém, sendo as carrocerias de madeira extintas e proibidas de circular. Entretanto, algumas das carrocerias em circulação já eram oriundas de segunda mão de outras cidades do sudeste brasileiro, uma prática ainda recorrente nos dias atuais em relação ao transporte de passageiros.

A organização do sistema só começou a tomar corpo com a criação da Região Metropolitana, em meados de 1973, em que nasceu a Companhia de Desenvolvimento e Administração da Área Metropolitana de Belém e os primeiros planos de desenvolvimento da região. Além disso, as questões dos agentes responsáveis pelo transporte sofreram alterações, passando para o Departamento de Trânsito do Pará (DETRAN, antigo CETRAN) e Departamento de Estradas e Rodagem (DER), conforme analisa Mercês (1998). 


\section{Memórias, transformações e modernidades na metrópole amazônica: \\ Uma breve história do transporte coletivo em Manaus e Belém}

Nesse contexto, algumas empresas tomaram corpo e foram sendo fundadas na região, sendo boa parte ainda pertencente ao sistema atual de Belém, como a Viação Monte Cristo, a Viação Forte, Rio Guamá e Guajará, sendo empreendimentos familiares e também, com algumas origens de outros países, tal como os primeiros empreendedores do transporte que atuavam de forma individual na cidade até meados dos anos 1960. Mercês (1998), destaca nesse processo de criação e manutenção das empresas, a presença de vários acionistas em outras

Os contextos posteriores, englobam nessa expansão, as áreas de expansão e também a destinação dos principais eixos viários, contribuindo para a inserção dos distritos de Icoaraci (vila do Pinheiro), ilha de Caratateua (Outeiro) e o Distrito de Mosqueiro, considerados um dos eixos de habitação e expansão habitacional junto com as demais regiões e municípios da Região Metropolitana.

\section{- Transferência Municipal, Expansão Urbana e os primeiros modelos de Terminais (1980 -} 2006)

Nos anos 1980, as configurações de organização do sistema de transporte coletivo, favoreceram a criação do primeiro órgão gestor metropolitano, a Empresa Metropolitana de Transportes Urbanos (EMTU) em 1982. Nesse contexto, a região Metropolitana era composta apenas por Belém e Ananindeua, mas já se encontrava em franca expansão para a criação dos municípios de Marituba e o já instalado município de Benevides, que também sofreria um reordenamento territorial, com a criação do município de Santa Bárbara do Pará.

Nesse contexto, as operações das empresas em algumas áreas eram com as linhas intituladas de "bagés". Mercês (1998, p.188), destaca a necessidade dessas linhas nas regiões sem infraestrutura como uma forma de garantir a demanda para posterior pedido de concessão. Isso era feito a margem dos processos de operação estabelecidos pelos órgãos gestores da região metropolitana. Além disso, é destacado o reordenamento sistemático de algumas linhas, abrangendo outras áreas de expansão e a criação de um sistema expresso e sistema parador das linhas em concessão.

A partir disso, novos modelos de concessão nos anos 1980, passaram a fortalecer também, a entidade que representa as empresas, neste caso, o Sindicato das Empresas de Transportes de Passageiros de Belém (SETRANSBEL), frente as hegemonias governamentais. Nota-se nesse contexto, o fortalecimento das atuações empresarias em algumas áreas, com disputas de atuação. Entretanto, em áreas limítrofes, ainda eram vistas como monopólio. Nesse contexto, é destacado a influência empresarial em algumas áreas.

Além desse contexto de monopólios, as inovações vindas para a cidade de Belém nos anos 1980 e 1990, se basearam na inserção de articulados na cidade e nos municípios da Região Metropolitana. Em primeiro momento, foi baseado em um ônibus com um vagão acoplado na traseira, posteriormente, inserindo-se no sistema, os modelos "sanfonados", já visto nas capitais brasileiras. Nesse contexto, destaca a Viação Forte e a Viação Perpétuo Socorro, a partir da ampliação das suas operações, tanto nas léguas 
patrimoniais de Belém, quanto nas áreas de expansão, o que favoreceu a compra desse modelo para suas linhas, conforme visto abaixo.

Figura 14: Frota da Viação Forte nos anos 1980

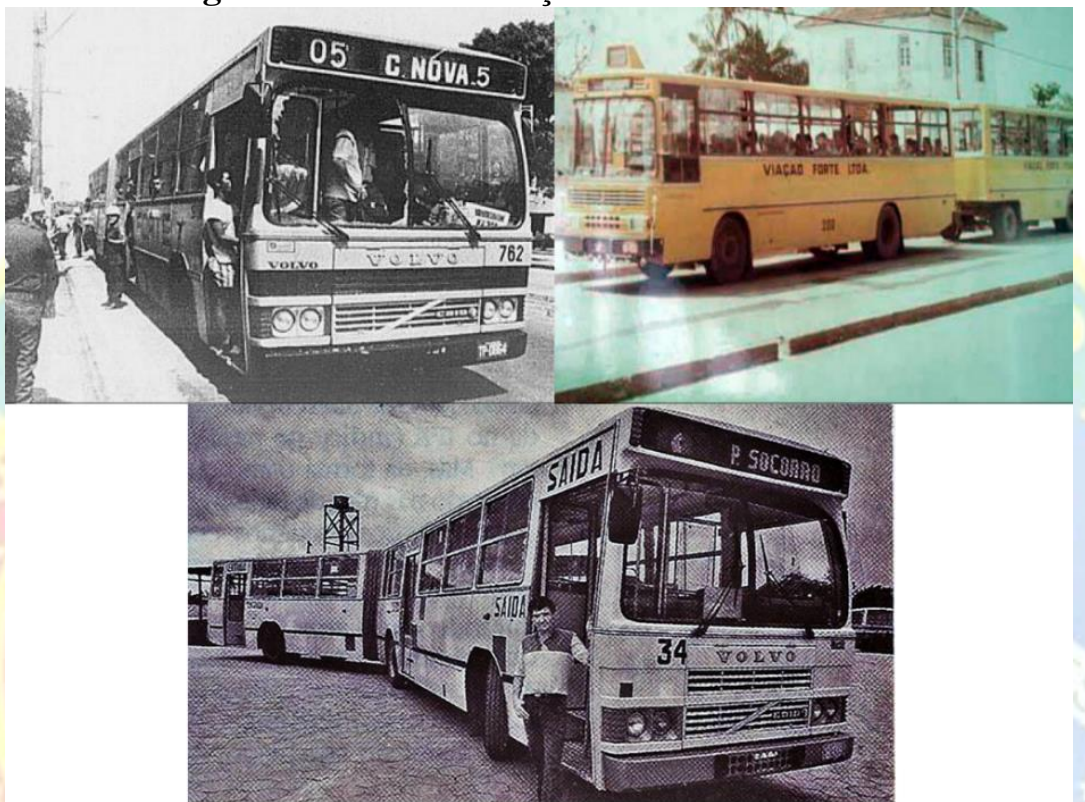

Créditos: Acervo de Lucas Jacó dos Santos, Robson Santos e Régis Carvalho

Além disso, a transferência de Gestão foi de suma importância no processo de organização do sistema de transporte. A municipalização de Gestão em Belém se deu apenas em 1990, com a criação da Companhia de Transportes de Belém (CTBel). Mercês (2005, p.91), destaca nesse processo da criação, a construção dos movimentos sociais em prol do transporte, característica que ganhou força na gestão municipal do então prefeito Edmilson Rodrigues, em que Vasconcelos (2001), já havia destacado a gestão participativa como um marco da quebra de monopólios em áreas estratégicas da Região Metropolitana de Belém.

Além dessa quebra de monopólio existente, começaram a surgir, por força das próprias concessionárias passaram a criar Estações Integradoras. Entre os municípios de Belém e Ananindeua, foram criadas as seguintes estações: BR-316 (Transmab), Coqueiro (Viação Forte) e Marex (Viação Perpétuo Socorro), onde as empresas realizavam transbordo das linhas dos bairros para a estação e do mesmo, para se dirigir as áreas centrais. Devidos a prejuízos administrativos, esse conceito foi abandonado em meados dos anos 2000, com sua estruturação total, no caso da Estação Marex, desativada em 2011, no âmbito de crise financeira da empresa, conforme visto abaixo. 
Figura 15: Da esquerda para direita: Estação Marex e Estação BR

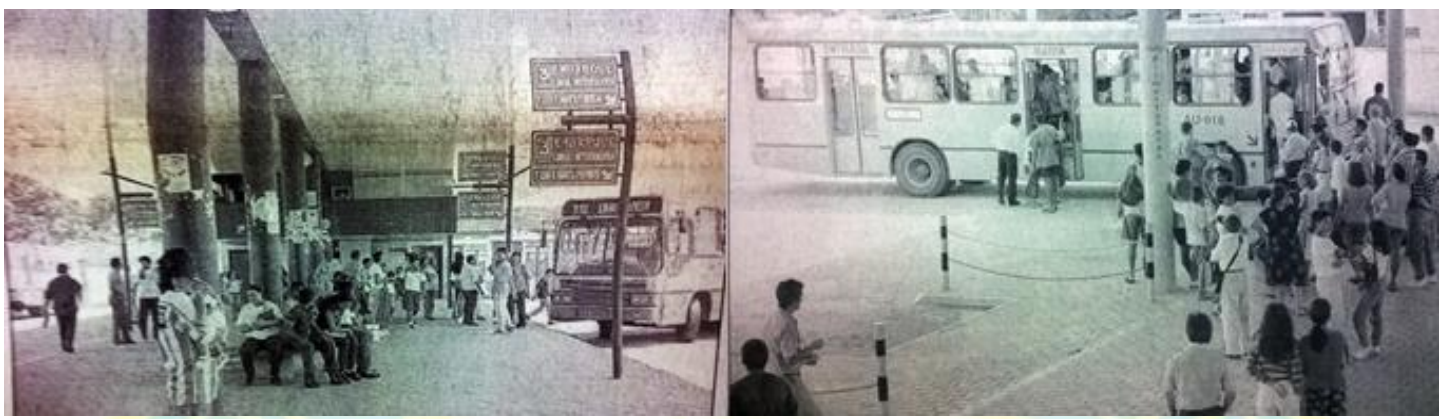

Créditos: Acervo de Lucas Jacó dos Santos

Nota-se nessa reorganização, as novas concepções de transporte, vinculadas principalmente ao poderio empresarial frente ao poder público. Com essa questão, os fatores de planejamento urbano se veem em situações posteriores de saturação, o que influenciará posteriormente nos projetos de novas linhas e posterior, nova reorganização do sistema de Belém e Região Metropolitana.

\section{- Projetos BR, Reestruturações Empresariais e a Primeira Licitação (2006 - atualmente)}

Nos anos 2000, o sistema de transportes chegou a contar com cerca de 40 empresas operantes na Região Metropolitana de Belém. Nesse processo, a falência e divisões se tornaram abundantes, principalmente pela transferência de ativos e passivos empresariais, que engloba funcionários, frota e principalmente, concessões de linhas. Castro et al (2014, p.100), destaca nesse processo, a absorção desse sistema a partir da ampliação dos agentes empresariais de maior e médio poder, principalmente pela caracterização de apropriação predatória e também, de renovações de frotas com carros de outras localidades.

Frente a essas mudanças, os primeiros projetos de Sistemas Tronco-Alimentadores foram criando forma na região, a partir dos planos entre o Governo do Estado do Pará e o Projeto de Cooperação com a JICA, que é uma agência de cooperação internacional do Japão. A primeira versão do BRT, pensada durante o mandato do então prefeito Duciomar Costa, era baseada exclusivamente no modelo adotado em Curitiba, relacionados a criação de Estações Tubo e faixas segregadas. Apesar desse planejamento, as obras foram realizadas sem um plano adequado e sem o porte de adequação a capital paraense, ocasionando a criação de CPI e sentenças recentes de ressarcimento ao erário público, conforme figura abaixo. 
Figura 16: Sistema BRT do prefeito Duciomar Costa

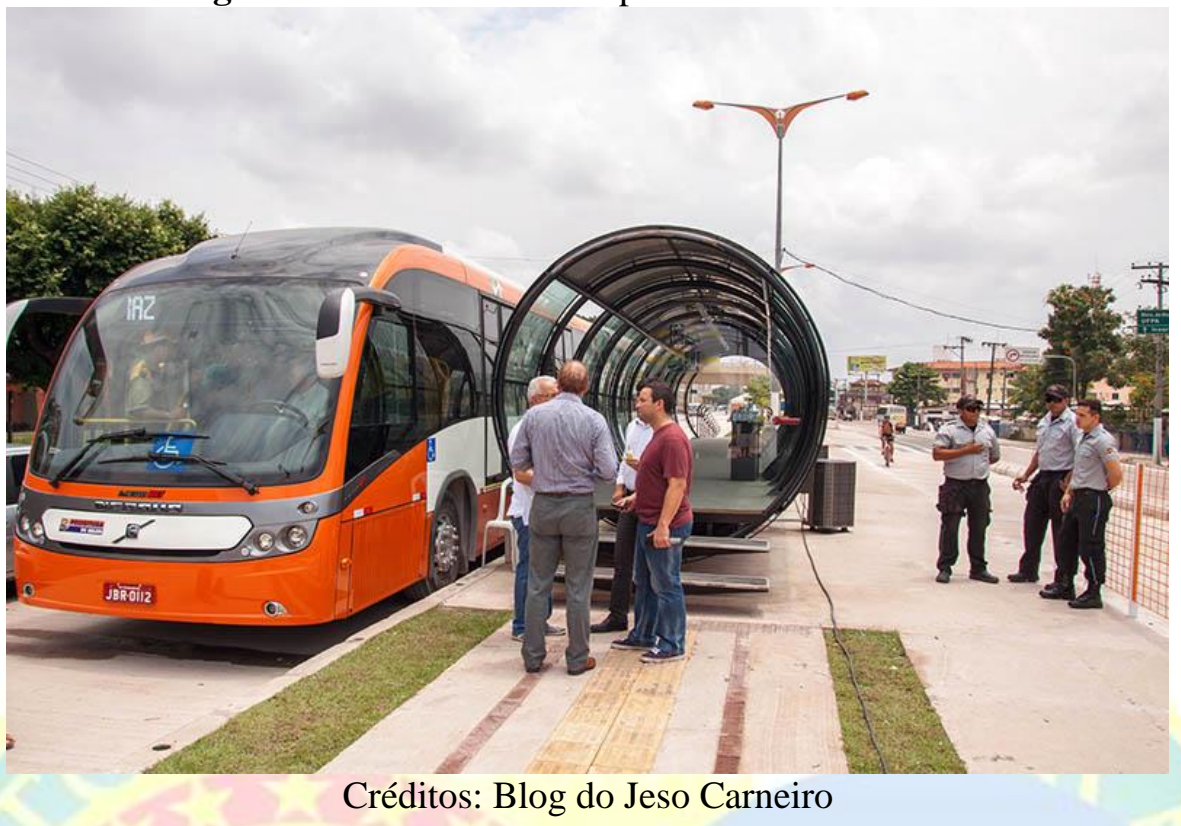

Além dessas questões de disputas empresarias, as questões políticas envolvendo o BRT também culminaram em novas transformações administrativas. Até 2011, a responsabilidade do sistema era por parte da CTBel, cuja transformação se deu em 2012, sendo transformada na AMUB (Autarquia de Mobilidade Urbana de Belém) e posteriormente, no ano de 2013, na sua atual configuração, a Superintendência de Mobilidade Urbana de Belém (SeMOB).

Nessas novas transformações, o novo projeto BRT Belém veio a ser também, recomposto, em um contexto de reconstrução das estruturas do antigo gestor, ocasionando novos aumentos e novas polêmicas acerca do projeto. Atualmente, o sistema é operante de forma gradativa desde meados de 2018 e corresponde a projeção do sistema BRT Metropolitano, este com conexão até o município de Marituba e já em processo de andamento das obras, conforme visto abaixo.

Figura 17: BRT Belém em operação e obras do BRT Metropolitano em Ananindeua (esquerda para a

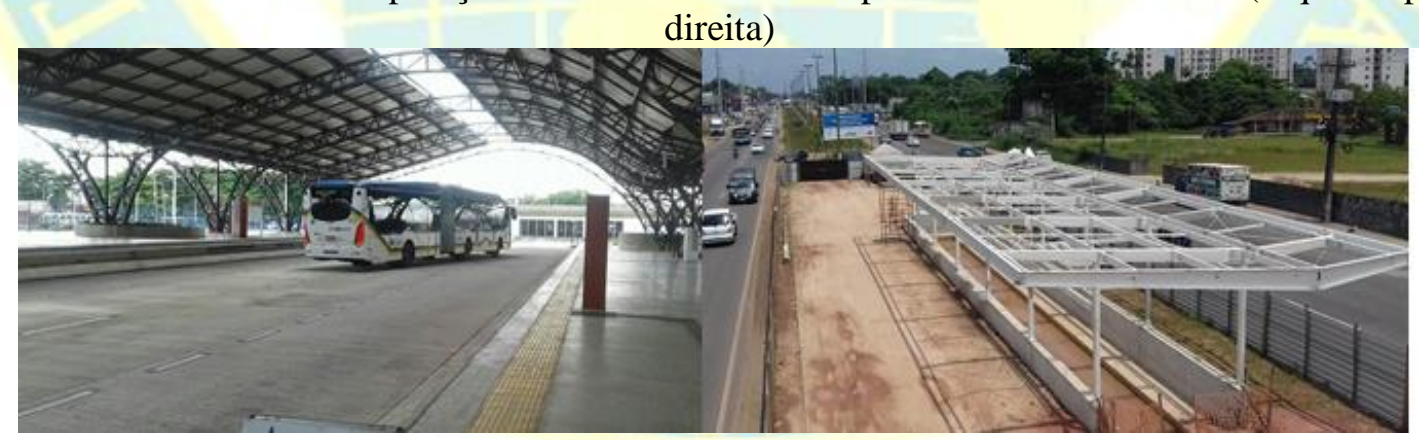

Créditos: Autor (2018, pesquisa de campo - BRT Belém) e Agência Pará

As configurações recentes de atuação empresarial, tanto em projetos, quanto em esforço empresarial, ganharam novas conotações a partir de 2014. Castro e Soares (2017), destaca uma nova reconfiguração dos 
monopólios das empresas de transporte, a partir dos conflitos e posterior relação hegemônica com o capital. É destacado nessa questão, o papel do estado nas fiscalizações e também, na cassação das operações de algumas empresas, todas de menor poder aquisitivo e já oriundas de outras divisões empresariais citadas anteriormente.

Nota-se, portanto, os fortalecimentos hegemônicos do capital empresarial no transporte de passageiro, correspondente também, as ampliações das áreas de atuação e a permanência no sistema de transporte. Apesar que, na conjuntura da realização dos primeiros procedimentos licitatórios, exigidos a partir da Lei nº666/93, a cidade de Belém ainda representa no seu porte de metrópole, uma regressão ao seu formato de organização, datadas de concessões e ordens de serviços precarizadas, além de uma concorrência com o transporte alternativo, presente de forma específica em algumas regiões.

Nesse processo específico do transporte alternativo, que são os serviços por vans, a diferenciação é a atuação restrita nos distritos de Icoaraci, Outeiro e Mosqueiro, além dos bairros da primeira légua, principalmente os mais afastados do Centro, como o Guamá, Terra Firme, a região da Estrada Nova. Conceição (2016; 2018), destaca nesse processo, a necessidade de regulamentação para o sanar das problemáticas envolvendo a precarização da operação e também do trabalho, além de habilitar os diálogos frente as questões futuras.

Com essas futuras projeções e projetos de transporte, a necessidade de um processo licitatório, é necessária. Nessa previsão, a divisão em bacias e tipologias de serviços locais, convencionais e vinculados também as integrações previstas do sistema BRT. Nisso, as concessões são previstas em uma escala de tempo e também, correspondente a investimentos em frota e também em extinção/supressão e reorganização das linhas existentes na cidade de Belém.

Entender as dinâmicas de transporte em Belém a partir da sua história, é compreender as transformações e tipologias vigentes. Segundo Lima (2011) e Pinho (2015), esses aspectos também se verificam a presença dos significados do transporte na sociedade, a partir das suas padronizações e também os ordenamentos territoriais que sofreram transformações ao longo dos anos, sobretudo em seus aspectos cosmopolitas a partir dos períodos de auge e decadência da economia, assim como enfatizado em relação a cidade de Manaus.

\section{CONSIDERAÇÕES FINAIS}

As histórias dos transportes nas cidades de Manaus e Belém estão relacionadas aos processos de expansão urbana e também os fatores econômicos em ambas as cidades, cujos processos estão interligados as diversas fases da história da Amazônia. Favorecidos também pelas relações comerciais, ambas as cidades também se conectaram acerca das novidades de transporte e de seus serviços conforme as necessidades e padrões vigentes. 
Além disso, os processos de expansão urbana, favoreceram a inserção de diversos modais de transporte, desde um aspecto formal, quando informal, gerando embates de disputa e posteriormente, problemáticas de omissão dos poderes em relação ao conter da clandestinidade e dos problemas a surgir. $\mathrm{O}$ pensamento do transporte urbano é relacionado também, aos fatores de novos usuários e também ao uso e ocupação do solo, no que diz a periferização do espaço e aos perfis de necessidades habitacionais frente ao uso do transporte coletivo.

Em ambas as cidades, os projetos de otimização do sistema exercem claramente, as inspirações dos modelos oriundos de outras regiões, mas em alguns momentos, partindo de princípios que englobam as suas particularidades e realidades locais. Entretanto, os entraves políticos e as políticas de gestão acabam por contribuir com as polêmicas contratuais e modificações nos projetos, o que geram instabilidades e adiamento das resoluções.

Portanto, a evolução e modernidade nas cidades amazônicas, estão em processos interligados, em aspectos políticos e econômicos, mas se diferenciam nas organizações e estruturações. De um lado, presença de capitais e evoluções empresariais de outras regiões, de outro, processos de organização e monopólios de décadas em um empresariado local. Nota-se, que os processos de organização no transporte tiveram as diversas participações das esferas públicas, mas relacionadas diretamente com o poderio empresarial, assim contribuindo ao mesmo tempo para uma evolução e modernidade, mas contribuindo para questões problemáticas estruturais na organização do sistema de transporte.

\section{AGRADECIMENTOS}

Este artigo é oriundo da monografia intitulada: "Entre idas e vindas: estudo de caso dos Sistemas de Transporte de Manaus e Belém, defendida pelo autor em abril de 2019, como obtenção do título de Bacharel em Geografia e fruto dos capítulos envolvendo ambas as cidades (sumarizado com Capítulo 2 e Capitulo 3 nesse trabalho). Agradecimento as agências de fomento, o Conselho Nacional de Desenvolvimento Científico e Tecnológico e a Fundação de Amparo à Pesquisa do Estado do Amazonas pelo fornecimento de bolsas entre os anos de 2017 a 2019.

\section{REFERÊNCIAS}

AB'SÁBER, Aziz Nacib. A cidade de Manaus: primeiros estudos. Boletim Paulista de Geografia, São Paulo, n. 15, p. 18-45, 1953.

CASTRO, Carlos Jorge Nogueira de. Transporte Público de Passageiros: uma análise sobre as Territorialidades das empresas de ônibus urbano regulamentadas na Região Metropolitana de Belém (2000-2012). 2015, 159f. Dissertação (Mestrado) - Universidade Federal do Pará - Programa de PósGraduação em Geografia, Belém.

CASTRO, Carlos Jorge Nogueira de: SOARES, Daniel Sombra. As Recentes Conformações Territoriais no Sistema de Transporte Público de Belém (2012-2015). In: SILVA, Christian Nunes; LIMA, Ricardo Revista do Instituto Histórico e Geográfico do Pará (IHGP), (ISSN: 2359-0831 - on line), Belém, v. 07, n. 02, p. 96 118, jul.-dez. / 2020. 
Ângelo Pereira; SILVA, João Márcio Palheta (Org.). Territórios, ordenamentos e representações na Amazônia. 1ed. Belém: GAPTA - UFPA, 2017, v. 1, p. 161-178.

CASTRO, Carlos Jorge Nogueira de; LIMA, José Julio Ferreira; SILVA, Christian Nunes; SOARES, Daniel Sombra. Novas Territorialidades do Sistema de Transporte Público de Passageiros: Estratégias para Continuidade dos Agentes Operadores (2008-2012). Boletim Amazônico de Geografia, v. 1, p. 94-104, 2014.

CASTRO, Carlos Jorge Nogueira de. Belém: Da Formação da Cidade à atuação dos Agentes do Sistema de Transporte Urbano. In: SILVA, Christian Nunes da; LUZ, Luziane Mesquita; PONTE, Franciney Carvalho; RODRIGUES, José Edilson Cardoso (Orgs.). Belém dos 400 anos: análises geográficas e impactos antropogênicos na cidade. 1ed.Belém: GAPTA UFPA, 2017, v. 1, p. 275-296.

CONCEIÇÃO, Suelen Reis da. A relação entre a gentrificação e as práticas de economia popular: o caso do Transporte Alternativo na Estrada Nova (PA). 2016, 58f. Trabalho de Conclusão de Curso (Licenciatura e Bacharelado em Ciências Sociais) - Universidade Federal do Pará, Belém.

CONCEIÇÃO, Suelen Reis da. Relações de poder na regulamentação do transporte alternativo em Belém: reflexos do poder local na política urbana. 2018, 123f. Dissertação (Mestrado em Sociologia e Antropologia) - Universidade Federal do Pará, Belém.

COSTA, Mikael Santana; PAIVA, Cristiano da Silva; SILVA, Victor Gabriel Borges da; COSTA, Valdenise Silva; SANTOS, Ana Jacqueline Leite dos. Processo Histórico dos Transportes em Manaus: Da Carroça, Bonde ao Ônibus Metalizado. In: Anais do $21^{\circ}$ Congresso Brasileiro de Transporte e Transito - ANTP, 2017, São Paulo - SP, julho de 2017, p.1-13.

DUARTE, Duarte. Transportamazon. Disponível em: http://idd.org.br/transportamazon/ - Acesso em: $05 / 01 / 2019$

LEMOS, Chélen Fischer de. O Processo sociotécnico de Eletrificação na Amazônia: articulações e contradições entre Estado, capital e território $\quad(1890 \quad$ a 1990). Tese (Doutorado em Planejamento Regional e Urbano). Universidade Federal do Rio de Janeiro Instituto de Pesquisa Planejamento Urbano e Regional - Programa de Pós-Graduação em Planejamento Urbano e Regional, Rio de Janeiro.

LIMA, Alexandre Martins de. Pelos trilhos dos bondes: cidade, modernidade e tensões sociais em Belém de 1869 a 1947. 2011. 425 f. Tese (Doutorado) - Universidade Federal do Pará, Núcleo de Altos Estudos Amazônicos - Programa de Pós-Graduação em Desenvolvimento Sustentável do Trópico Úmido, Belém.

LIMA, Alexandre Martins de. Pelos trilhos dos tramways: modernidade e urbanidade em Belém do Pará de 1869 a 1947. In: Seminário Internacional Amazônia e fronteiras do conhecimento, 2008, Belém: Ed. NAEA, 2008. p. 1-17.

LIMA, Marcos Castro de. $O$ ir e vir urbano: Uma análise sobre o transporte coletivo em Manaus entre 1980 e 2000. 2005, 164f. Dissertação (Mestrado) - Universidade Federal do Amazonas - Programa de PósGraduação em Sociedade e Cultura na Amazônia, Manaus.

MAGALHÃES, Soraia Pereira. O transporte coletivo urbano de Manaus: bondes, ônibus de madeira e metálicos. 1. ed. Manaus: EDUA, 2014. 260p.

MERCÊS, Simaia do Socorro Sales das. Mudanças e continuidades na provisão do transporte coletivo em Belém. In: XII Encontro da Associação Nacional de Pós-graduação e Pesquisa em Planejamento Urbano e Regional. 2007, Belém - PA, maio de 2007, p.1-21.

Revista do Instituto Histórico e Geográfico do Pará (IHGP), (ISSN: 2359-0831 - on line), Belém, v. 07, n. 02, p. 96 118, jul.-dez. / 2020. 
MERCÊS, Simaia do Socorro Sales. Transporte coletivo em Belém: mudança e continuidade. 2005, 313f, Tese (Doutorado) - Universidade de São Paulo - Programa de Pós-Graduação em Arquitetura e Urbanismo, São Paulo.

MERCÊS, Simaia do Socorro Sales. Transporte urbano por ônibus na Região Metropolitana de Belém (1966-1983): a formação da questão. 1998, 262f. Dissertação (Mestrado) - Universidade de São Paulo Programa de Pós-Graduação em Arquitetura e Urbanismo, São Paulo.

OLIVEIRA, José Aldemir; MAGALHÃES, Soraia Pereira. A circulação na Manaus da Belle Epoque: a modernização selvagem. Mercator (UFC), v. 2, p. 45-56, 2004.

ONIBUS BRASIL. Acervo de Lucas Jacó dos Santos. Disponível em: https://onibusbrasil.com/lucasjaco - Acesso em: 19/04/2020.

ONIBUS BRASIL. Acervo de Régis Carvalho. Disponível em: https://onibusbrasil.com/regiscarvalho - Acesso em: 19/04/2020.

ONIBUS BRASIL. Acervo de Robson Santos. Disponível em: https://onibusbrasil.com/robinhobr - - Acesso em: 19/04/2020.

PINHO, Fernando Augusto Tavares. A volta do bonde a Belém: cidade, discurso e saudade. 2015. 269 f. Tese (Doutorado em Planejamento Urbano e Regional) - Universidade Federal do Rio de Janeiro, Instituto de Pesquisa e Planejamento Urbano e Regional, Rio de Janeiro.

PINHO, Fernando Augusto Tavares. Festas, inaugurações e decepções: a implantação dos bondes elétricos em Belém. 2001, 58f. Monografia (Especialização em História da Amazônia) - Universidade Federal do Pará - Instituto de Filosofia e Ciências Humanas, Belém.

RODRIGUES, Paulo Ricardo de Souza. Considerações sobre a viabilidade econômica de implantação BRT/VLT no transporte coletivo em Manaus. 2017, $130 \mathrm{f}$. Trabalho de Conclusão de Curso (Engenharia Civil) - Faculdade Metropolitana de Manaus, Manaus.

SANTOS, Dhyene Vieira dos. Motoristas e Condutores de Bondes: Sociabilidade, cultura associativa e greves (1899-1930). 2020, 163f. Dissertação (Mestrado em História) - Universidade Federal do Amazonas Programa de Pós-Graduação em História, Manaus.

SANTOS, Milton. A natureza do espaço: técnica e tempo, razão e emoção. São Paulo: Hucitec, 2004.

TOBIAS, Maisa Sales Gama; COUTINHO NETO, Benedito; NEVES, Patrícia Bittencourt. As faces da Entropia do Transporte Urbano na Amazônia: o caso de Belém do Pará - Brasil. Revista dos Transportes Públicos, v. 199/20, p. 99-110, 2009.

TOBIAS, Maísa Sales Gama. Custo Transporte e Indicadores de Mobilidade Urbana na RMB. 1. ed. Belém: Unama, 2005.

VASCONCELOS, Eliza Maria Almeida. Gestão Democrática e Participação Popular: Uma análise da Política de Transporte do Município de Belém. In: $13^{\circ}$ Congresso de Transporte e Trânsito - ANTP, 2001, p.1-8. 